\title{
M\&A AND PARTNERING AS EXTERNAL CORPORATE GROWTH STRATEGIES - AN AHP/ANP-BASED DECISION TOOL
}

\author{
Axel Rossdeutscher \\ Institute of Co-operative Systems \\ University of Münster \\ Haltern am See, NRW, Germany \\ E-mail: axel@rossdeutscher.net
}

\begin{abstract}
In order to sustain their competitiveness companies pursue different growth strategies. As crucial factors like time and know-how limit the companies' abilities to exercise internal growth strategies, Mergers \& Acquisitions (M\&A) and Partnering strategies emerge as alternative organization modes of external corporate growth. To enable decision makers within companies to choose the appropriate growth strategy, the essential influencing factors are composed into a consistent factor framework. Several decision theory-based methods are compared in order to identify the adequate methodology to transform the set of influencing factors into a decision tool for corporate managers. The Analytic Hierarchy Process / Analytic Network Process (AHP/ANP) turned out to be that method of choice. With the help of pairwise comparisons the importance of each influencing factor can be precisely determined by the actors involved in decisions between different external corporate growth options. The derivation of this AHP/ANP-based decision tool and the subsequent illustration of an in-depth case study in the retail industry thus provide valuable advancement to both academic knowledge and managerial practice in terms of reasonable decision making.
\end{abstract}

Keywords: M\&A, partnering, external corporate growth, alternatives, AHP, ANP, case study.

\section{Introduction}


ISAHP Article: Rossdeutscher / M\&A and Partnering as external corporate growth strategies an AHP/ANP-based decision tool.

The overall goal of this study is to provide decision makers in companies with an easily applicable decision tool in order to choose the adequate external growth strategy for their individual purposes. The underlying research question is how should companies decide between M\&A transactions and Partnering strategies? To solve this research question is of high interest in the managerial practice because of two reasons: High failure rates and similar motives. After a vast body of relevant literature was reviewed there are clear indications that the reasons for companies to pursue M\&A or to engage Partnering activities like alliances are largely alike. In addition the majority of studies focusing on M\&A and Partnering as important parts of corporate strategies prove high failure rates. Obviously, there is a high uncertainty among decision makers in companies of when to employ which growth strategy. To offer support, a decision tool based on the Analytic Hierarchy Process / Analytic Network Process is developed and put into practice.

\section{Literature Review}

In a series of interviews with U.S. American corporate managers, both organization modes (M\&A and Partnering) were identified as equivalent external growth strategies by 82 percent of the interviewees. Surprisingly enough, in only 14 percent of the analyzed companies there were managerial instruments that allowed a profound comparison between the two strategies (Dyer \& Kale \& Singh, 2004). Furthermore, a review of relevant literature in the context of the research problem addressed here shows that the topic is either discussed in fragments only or with regard to specific aspects, organization modes and theoretical concepts. There are extremely few studies (Dussauge \& Garrette 2000, Hagedoorn \& Duysters 2002, Hoffmann \& Schaper-Rinkel 2001) which systematically attempt to provide comprehensive support for a general decision between M\&A and Partnering as external corporate growth strategies. To fill this academic void this study introduces an easily applicable decision tool to choose the ideal external growth strategy.

\section{Hypotheses/Objectives}

The main objective of the study is the establishment of a structured framework which includes the appropriate theoretical foundations as well as the relevant factors influencing the decision between M\&A and Partnering. A systematic presentation of those factors and subsequent development of a prototypical (complete) set of influencing factors provide a basis for the following analyses. The theoretical findings are supported by positive statements from semi-structured interviews with a group of industry experts. In addition several methods of multi criteria decision making are checked against each other to identify the most appropriate method for choosing the ideal external growth strategy, namely the AHP/ANP method. The determined influencing factors are then implemented into the AHP/ANP procedures to develop a decision routine or tool for companies, which have to decide between an M\&A-transaction and some kind of Partnering approach. The whole process cycle starting with the formulation of the decision problem and ending with practical conclusions for the corporate managers is presented and documented in a case study.

\section{Research Design/Methodology}

International Symposium of 
ISAHP Article: Rossdeutscher / M\&A and Partnering as external corporate growth strategies an AHP/ANP-based decision tool.

The study uses a thorough literature review in combination with interviews of experts to identify the set of relevant (types of) factors influencing the decision between M\&A and Partnering as different external growth strategies (goal, criteria, sub-criteria, alternatives). In the case study, a standard AHP/ANP model (distributive mode) is applied, the pairwise comparions and the calculations of consistency, local and global weights have been performed with the help of the SuperDecisions software. The decision tool / model also supports the aggregation of different people's opinions (methods: geometric mean, consensus, balloting).

\section{Data/Model Analysis}

Offering an easy to use decision tool composed of a prototypical set of influencing factors enables corporate management to come to a reasonable decision between M\&A and Partnering. In the case study the complete factor-set is being used by the decisionmakers:

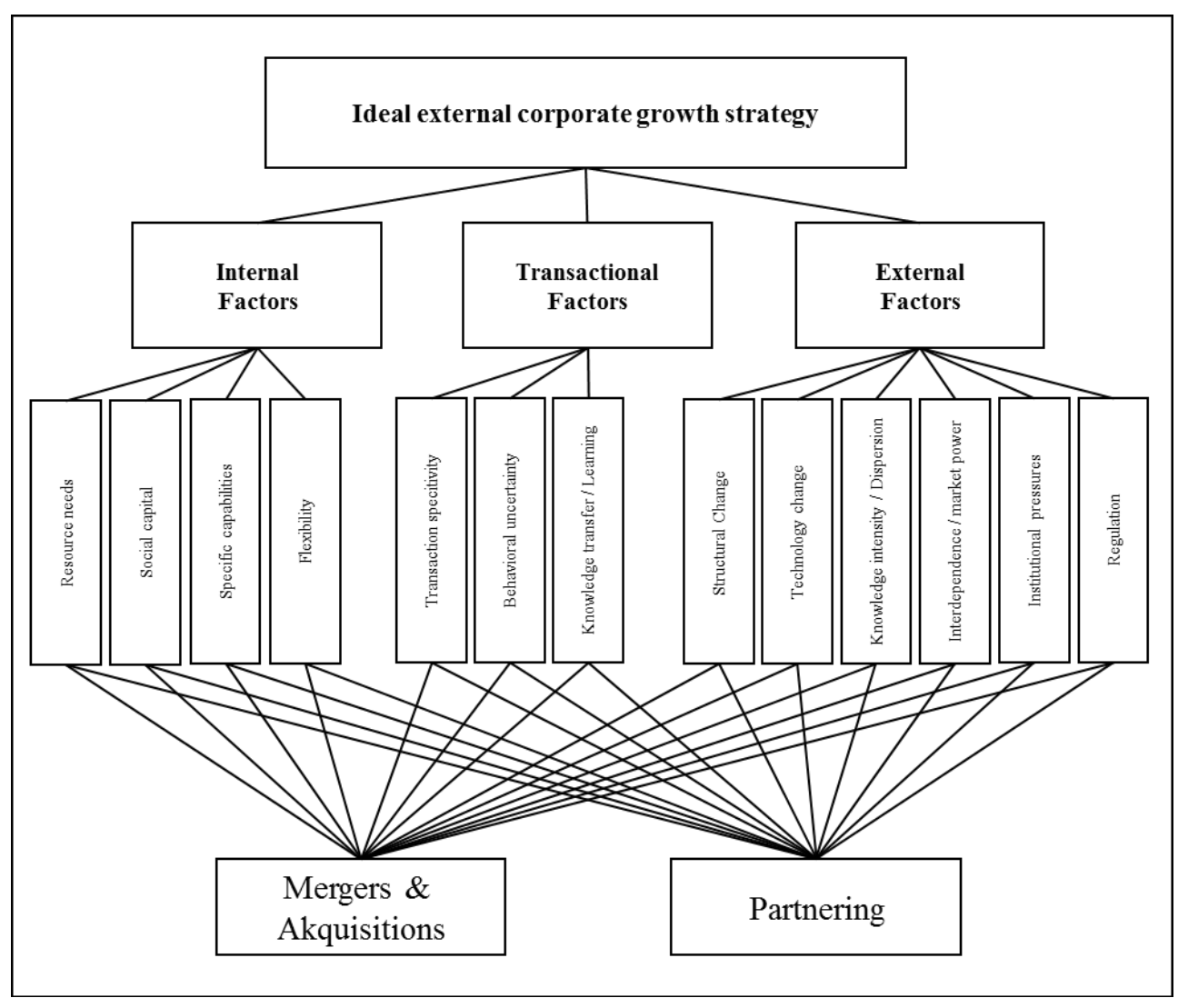

Following the AHP/ANP logic, pairwise comparisons between criteria / goal, sub-criteria / criteria und alternatives / sub-criteria are made and validated with the help of consistency index, random index und consistency ratio (inconsistency threshold $\mathrm{CR}=$ $0,1)$. As an example, the pairwise comparisons between criteria w.r.t. the overall goal are shown:

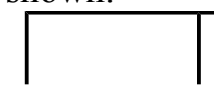

International Symposium of the Analytic Hierarchy

Process
Washington, D. C. June 29 - July 2, 2014 
ISAHP Article: Rossdeutscher / M\&A and Partnering as external corporate growth strategies an AHP/ANP-based decision tool.

\begin{tabular}{|c|c|c|c|c|c|c|c|c|c|c|c|c|c|c|c|c|c|c|}
\hline $\begin{array}{c}\text { Element } \\
1\end{array}$ & 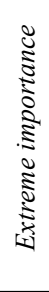 & & 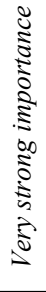 & & 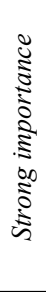 & & 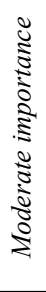 & & 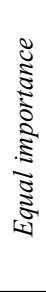 & & 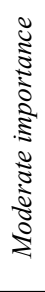 & & 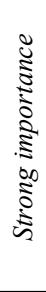 & & 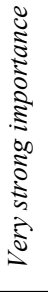 & & 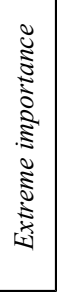 & Element 2 \\
\hline $\begin{array}{l}\text { internal } \\
\text { factors }\end{array}$ & 9 & 8 & 7 & 6 & 5 & 4 & 3 & 2 & 1 & 2 & 3 & 4 & 5 & 6 & 7 & 8 & 9 & $\begin{array}{c}\text { transactional } \\
\text { factors }\end{array}$ \\
\hline $\begin{array}{l}\text { internal } \\
\text { factors }\end{array}$ & 9 & 8 & 7 & 6 & 5 & 4 & 3 & 2 & 1 & 2 & 3 & 4 & 5 & 6 & 7 & 8 & 9 & $\begin{array}{l}\text { external } \\
\text { factors }\end{array}$ \\
\hline $\begin{array}{c}\text { transactional } \\
\text { factors }\end{array}$ & 9 & 8 & 7 & 6 & 5 & 4 & 3 & 2 & 1 & 2 & 3 & 4 & 5 & 6 & 7 & 8 & 9 & $\begin{array}{l}\text { external } \\
\text { factors }\end{array}$ \\
\hline
\end{tabular}

As a result the local weights (including consistency check) can be quantified:

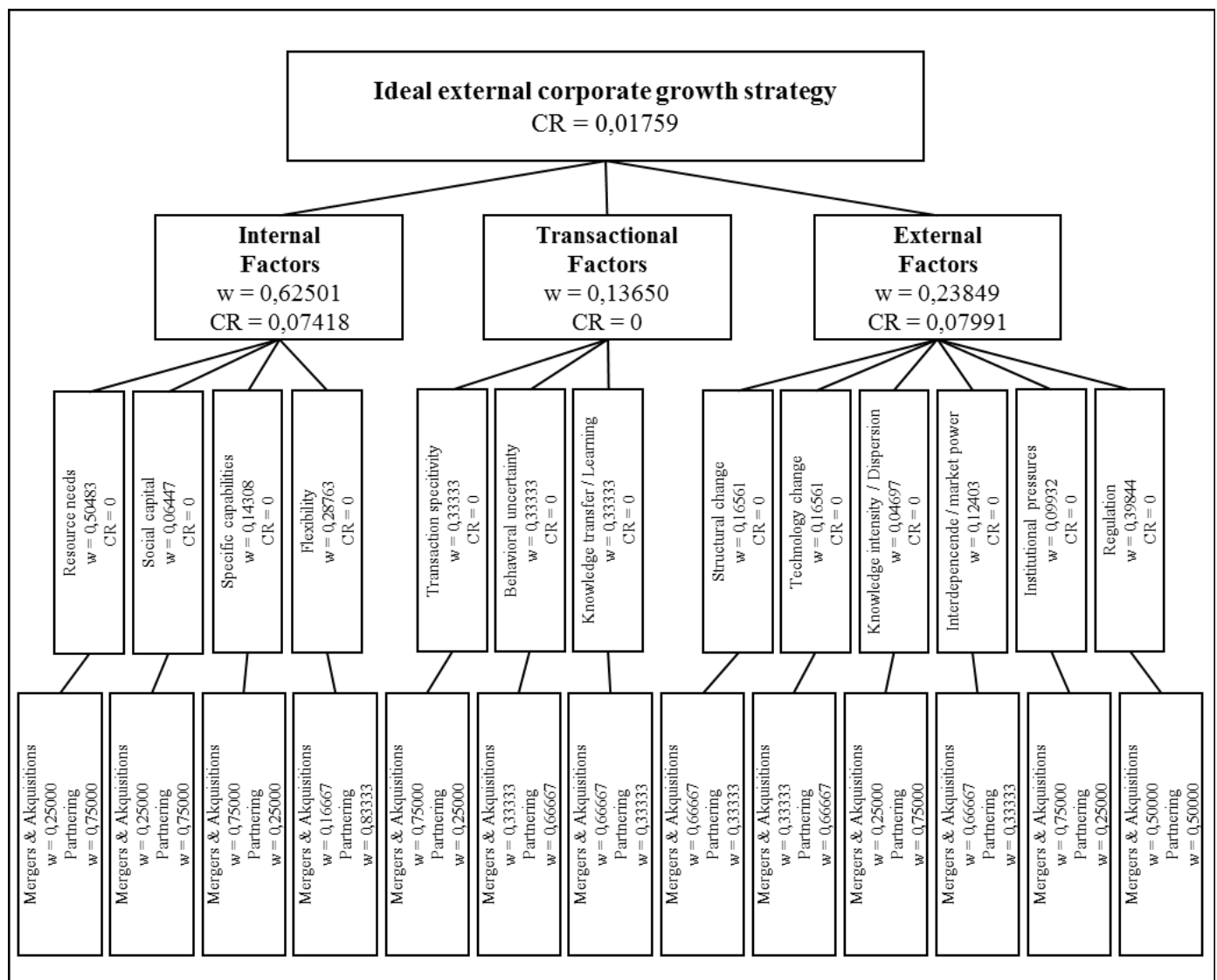

Finally, the global weights are calculated and the best growth strategy can be identified.

\section{Limitations}

International Symposium of

Washington, D. C. the Analytic Hierarchy June 29 - July 2, 2014

Process 
ISAHP Article: Rossdeutscher / M\&A and Partnering as external corporate growth strategies an AHP/ANP-based decision tool.

The study results can only display a subjective part of a more complex decision environment in reality. Therefore the recommended growth strategy calculated by the AHP/ANP model is not necessarily put into practice by those managing the company. In addition it has to be stated that the identified influencing factors make no claim to be complete or exhaustive. In the individual corporate decision process there may be several important factors which are not included in the factor set, which was introduced in this study.

\section{Conclusions}

Over the last decade, fundamental changes have forced companies to redefine their scope and reach. Therefore they tend to growth externally through M\&A transactions or Partnering approaches. Nonetheless there appears to be high uncertainty among managers who have to choose between those two growth strategies. The academic void of systematically identifying relevant factors influencing the decision between M\&A and Partnering and composing an AHP/ANP driven decision tool to help managers decide reasonably is thus filled by this study.

Of course there are limitations and enough starting points for further research. For example the introduced decision tool only focuses on the fundamental decision between M\&A and Partnering. Refining the model alternatives, e.g. alliances, joint ventures, contractual agreements, acquisitions or mergers could be an extremely valuable enrichment. In recent years more and more publications deal with the topic of sequential choice of organization modes. Due to high failure rates, companies tend to follow Partnering approaches before finally acquiring a certain target when things turn out positively. Adding this topic into the decision tool would further widen the tool's scope of application. Finally, the identification of relevant influencing factors was conducted theoretically and supplemented by a few interviews with industry experts. Empirical inquiries or larger samples of interviews would be extremely helpful.

\section{Key References}

Dussauge, P. \& Garrette, B. (2000). Alliances versus acquisitions: choosing the right option. European Management Journal, 18, 63-69.

Dyer, J. H. \& Kale, P. \& Singh, H. (2004). When to ally and when to acquire. Harvard Business Review, 108-115.

Hagedoorn, J. \& Duysters, G. (2002). External sources of innovative capabilities: the preference for strategic alliances or mergers and acquisitions. Journal of Management Studies, 39, 167-188.

Hoffmann, W. H. \& Schaper-Rinkel, W. (2001). Acquire or ally?. Management International Review, 41, 131-159. 